Niğde Ömer Halisdemir Üniversitesi Mühendislik Bilimleri Dergisi
Niğde Ömer Halisdemir University Journal of Engineering Sciences

\title{
Hibrit kompozitlerin mekanik özelliklerine ve darbe davranışına fonksiyonelleştirilmiş nanokil ilavesinin etkisi
}

\section{The effect of functional nanoclay addition on the mechanical properties and impact behavior of hybrid composites}

\author{
Ümran Esendemir1,* (iD), Recep Şimşek ${ }^{2}$ (D), Mehmet Fahri Saraç3
}

\author{
${ }^{I}$ Süleyman Demirel Üniversitesi, Makine Mühendisliği Bölümü, 32260, Isparta, Türkiye \\ ${ }^{2}$ Süleyman Demirel Üniversitesi, Fen Bilimleri Enstitüsü, Makine Mühendisliği Anabilim Dall, 32260, Isparta, Türkiye \\ ${ }^{3}$ Süleyman Demirel Üniversitesi, Otomotiv Mühendisliği Bölümü, 32260, Isparta, Türkiye
}

\section{Özet}

Bu çalışmada, cam elyaf/kevlar-epoksi hibrit kompozitlerin mekanik özelliklerine ve darbe davranışlarına fonksiyonellendirilmiş nanokil (silan ve amine gruplu) ilavesinin etkisi deneysel olarak incelenmiştir. Epoksi reçineye üç farklı konsantrasyonda $(\% 0, \% 1$, ve $\% 3)$ fonksiyonellendirilmiş nanokil karıştırılmıştır. 12 tabakalı kompozit numuneler el yatırma yöntemiyle üretilmiştir. Üretilen kompozitlerin mekanik dayanımları ve 30J altında yapılan darbe davranışları incelenmiştir. Nanokil ilavesiz ile ilaveli numuneler arasındaki karşılaştırmalar temas kuvveti, çökme, darbe enerjisi, hız ve zaman verileri kullanılarak yapılmıştır. Ağırlıkça \%1 nanokilli kompozit malzemenin hem mekanik özellikler açısından hem de darbe direnci açısından daha iyi bir performans sergilediği görülmüştür. $\quad \% 1$ nanokil ilaveli numunelerde kilin matriks-fiber ara yüzeyinde iyi dağılması sonucunda çökme değerleri \%10 azalmış ve yük taşıma kapasitesini $\% 22$ oranında artmasının yanında $23.60 \mathrm{HV}$ sertlik değeri ile saf ve \%3 kil katkılı hibrit kompozitlerden ayrilmaktadır.

Anahtar kelimeler: Hibrit kompozit, Nanokil, Darbe davranışı, Hasar, Düşük hızlı darbe

\section{Giriş}

İnsan ihtiyaçlarının değişmesi ve teknolojinin geldiği nokta itibarıyla günümüzde farklı özelliklere sahip, daha fonksiyonel malzemelere gereksinim de artmıştır. $\mathrm{Bu}$ kapsamda son yıllarda kompozit malzemelere olan talebinde hızlıca artması bu tür malzemelerin yapı, özellik ve performansların geliştirilmesine olanak sağlamıştır.

Kompozit malzemeler kullanım alanlarına bağlı olarak darbelere maruz kalmakta ve kullanım ömürlerini sınırlandırmaktadır. $\mathrm{Bu}$ sebep ile Üretimleri yapılan kompozitlerin darbelere karşı göstermiş oldukları düşük veya yüksek hızda karşılaştıkları dirençlere karşı gösterdikleri davranışlar büyük önem arz etmektedir [1]. Bu kapsamda son yillarda polimer esaslı elyaflar ile

\section{Abstract}

In this study, the effect of functionalized nanoclay (with silane and amine groups) on the mechanical properties and impact behavior of glass fiber / Kevlar-epoxy hybrid composites was experimentally investigated. Nanoclay functionalized at three different concentrations $(0 \%, 1 \%$, and 3\%) was mixed into the epoxy resin. Composite samples with layer 12 have been manufactured by handlayup method. The mechanical properties and impact behaviors under $30 \mathrm{~J}$ were examined on the prepared composites. The comparisons between the nanoclay and non-nanoclay samples were carried out by using contact force, deflection, impact energy, velocity and time data of the impact tests. Mechanical strength and impact properties of $1 \%$ nanoclay added hybrid composites how better performance than that of $0 \%$ and $3 \%$ nanoclay added hybrid composites. As a result of the good dispersion of clay in the matrix-fiber interface in samples with $1 \%$ nanoclay addition, the impact values are reduced by $10 \%$ and load bearing capacity is increased to $22 \%$. Futhermore, among bare and 3\% nanoclay added hybrid composites, the highest hardness value of $23.60 \mathrm{HV}$ obtained from $1 \%$ nanoclay added hybrid composite structures.

Keywords: Hybrid composite, Nanoclay, Impact behavior, Damage, Low velocity impact

güçlendirilmiş yapılar üzerindeki yapılan çalışmalara olan ilgi gün geçtikçe artmaktadır [2].

Aktaş vd. [3] çalışmalarında farklı darbe enerjilerinde cam/epoksi kompozit plakaların davranışlarını incelemişlerdir. Cam elyafın yoğun olmasından kaynaklı gevrek yapının varlığı düşük darbe enerjilerinde matris çatlağ 1 gösterirlen yüksek darbe enerjilerinde fiber kırılmalarına sebebiyet vermiştir. Bir başka çalışma da ise, Valença vd. [4] cam ve cam/kevlar kompozit yapıların darbe davranıșlarını incelenmiş ve kevlar içeren kompozit yapılarda çekme mukavemeti, darbe enerjisi ve eğme mukavemetlerinin \%20-30 oranında yüksek olduğunu tespit etmişlerdir. Kaştan vd. [5], 10 farklı kompozisyonda yapmış oldukları çalışmada $\% 1, \% 3$ ve $\% 5$ nanokil ilavesi ile elastisite modüllerinde sırasıyla $\% 13, \% 38,6$ ve $\% 63$ artış

\footnotetext{
* Sorumlu yazar / Corresponding author, e-posta / e-mail: umranesendemir@ sdu.edu.tr (Ü. Esendemir)

Geliș / Recieved: 27.08.2020 Kabul / Accepted: 05.04.2021 Yayımlanma / Published: 27.07.2021

doi: 10.28948/ngmuh.786231
} 
meydana geldiğini tespit etmişlerdir. Ferreira vd. [6] ise nanokil katkılı kevlar kompozitlerin nanokil artışı ile statik mukavemetlerinin azalıp, sertliğini arttırdığ 1 görülmüş olup nanokil katkılı kompozitlerin \%12'ye varan yorulma mukavemetlerinde iyileşme görülmüştür. Krushnamurty vd. [7] benzer şekilde modifiye montimorrilanit nanokil ilavelerinde (\%0 ile $\% 5$ arasında değişen) sertleşmenin (kürlemenin) daha hızlı olduğu ve epoksi matrisin kırılma tokluğunu iyileştirildiği görülmüştür. Rafiq vd. [8] ise cam elyaf takviyeli epoksi kompozitlere nanokil ilavesi (\%0, $\% 1.5$ ve \%3) ile numunelerin sertliğinin arttığını ve ağırlıkça $\% 1,5$ oranında nanokil ilaveli numunelerde maksimum yükte $\% 23$ iyileşme ve sertlikte \%11 artış olduğunu gözlemlemişlerdir. Uyaner vd. [9], cam/epoksi tabakalı kompozitlerde plaka boyutlarının darbeye dayanımlarını incelediklerinde kompozit plakanın kalınlığı arttıkça (50mm'den 150mm'ye) malzeme üzerindeki kalıcı çökme miktarının azaldığını belirtmişlerdir. Reis vd. [10], yaptıkları çalışmada ise kevlar esaslı epoksi kompozitlerde tabakalar arası darbe davranışlarını geliştirmek için epoksi içerisine takviye malzeme olarak mantar tozu ve nanokil kullanılmışlardır. Nanokil malzemenin yüzeyindeki silan grupların reçine ile aynı organik yapıda olmalarından ötürü uyumlu olmaları dolgu malzemelerin reçine içerisinde homojen olarak dağılmalarını sağlamıştır. Bu durum, kompozit yapının maksimum darbe yükünü, elastisitesini, çekme dayanımını arttırmasının yanı sıra çökmeyi azalttığ görülmüştür. Öner vd. [11], yaptıkları çalışmada karbon nanotüp (KNT) ilaveli cam elyaflı kompozitlerin takviyesiz yapılara göre çekme ve eğilme dayanımını \%0.75'e kadar arttırdığı fakat artan KNT ilavesi ile epoksi içerisindeki topaklaşmadan kaynaklı kompozit yapılarda eğilme dayanımlarının düşük olduğu görülmüşsür. Son olarak, Mahdi vd. [12], yaptıkları çalışmada KNT'ler ve nanokili aynı anda fiber takviyeli plastik yapılarda KNT'leri ve nanokilin darbe özelliklerinin düşük oranlarda $(<\% 10)$ eklenmesi durumunda geliştiğini ve darbe hasar alanlarının azaldığını tespit etmişlerdir.

Kompozit malzemeler günümüzde pek çok iş sahasında özellikle inşaat, rüzgâr enerjisi, otomotiv, uzay ve havacılık gibi birçok sektörde çok önemli bir yere sahiptir. $\mathrm{Bu}$ sektörlerde malzemelerin mukavemeti, tokluğu ve hafifliği gibi özellikleri çok büyük rekabet ortamı yaratmaktadır. Literatürde cam elyaf/kevlar hibrit kompozitlerin hem mekanik özelliklerinin ve hem de darbe davranışı üzerine nanokilin etkisi üzerine yapılmış çok fazla çalışmaya rastlanılmamıştır. $\mathrm{Bu}$ amaçla bu çalışmada fonksiyonellendirilmiş (silan ve amino gruplu) nanokil ilavesinin (\%0, \%1 ve \%3) kompozit malzemenin mekanik özelliklerine ve darbe davranışına etkisi deneysel olarak incelenmiştir.

\section{Materyal ve metot}

\subsection{Kompozit malzemenin üretimi}

$\mathrm{Bu}$ çalışma da fiber malzemesi olarak kullanılan aramid elyaf kumaş Dupont firmasının ürettiği $207 \mathrm{~g} / \mathrm{m}^{2}$ yoğunluğa sahip Kevlar-49 kodlu ürün kullanılmıştır. Matriks malzemesi olarak Kompozitsan, İzmir firmasından tedarik edilen F-1564 epoksi ve F-3486 reçine sertleştiricisi tedarik edilmiştir. Takviye elemanı olarak kullanılan (yüzeyi modifiye edilmiş, ağırlıkça \%0.5-5 aminopropiltrietoksisilan, \%15-35 oktadesilamin esaslı nanokil ile Sigma-Aldrich'ten alınmış olup karakteristik yapısı Saraç vd. [13] çalışmasında detaylıca bahsedilmiştir.

Kompozit malzeme üretiminde önce kevlar ve cam elyaflar istenilen boyutta kesilerek, tartımı yapılmıştır. Kevlar ve cam elyafin ağırlıkça $1 / 1$ oranında epoksi ve epoksinin de \%34 ü oranında sertleştirici ilave edilerek hazırlanan karışıma \%0, \%1 ve $\% 3$ oranında nanokil ilave edilmiş ve Şekil 1'de gösterilen MS 3040D model karıştırıcı ile 1250 devirde 1 dakika boyunca karıştırılmıştır.

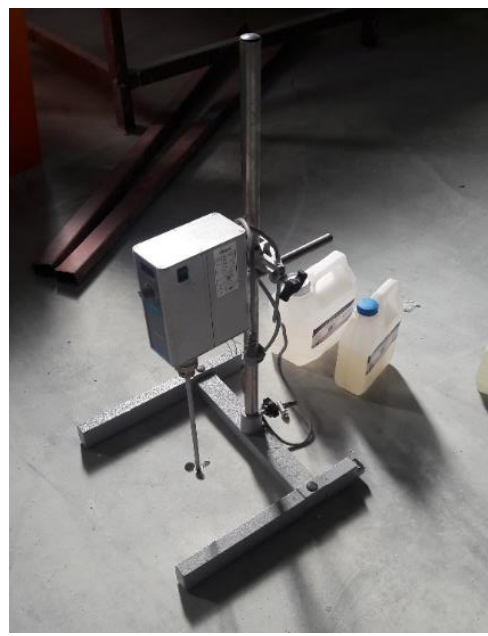

Şekil 1. Mekanik karıştırıcı

Nihai karışım, üzerine kalıp ayırıcı PVA sürülmüş ve 12 katman halinde (3 kat kevlar - 1 kat örgü cam elyaf) elle yatırma yöntemi tatbik edilmiştir. Elle yatırma işlemi esnasında katmanlar arasında hava boşluğunun oluşmaması için, hazırlanan numunelere 12 saat vakumlama işlemi uygulanmıştır (Şekil 2).

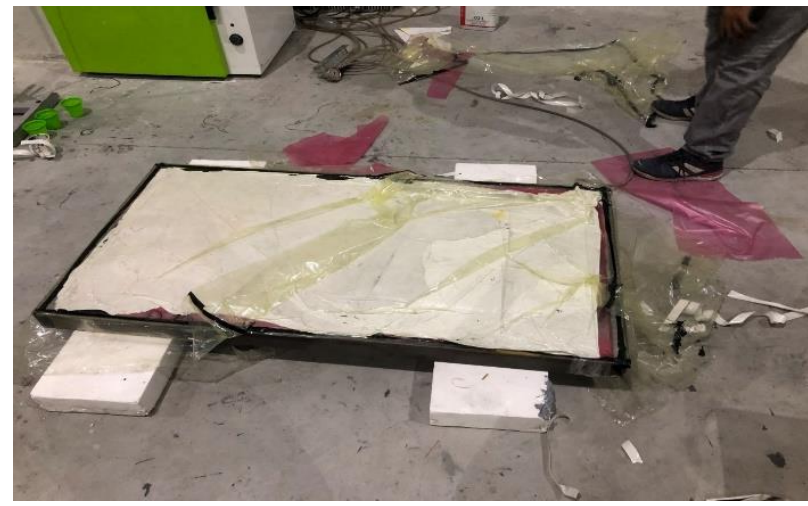

Şekil 2. Vakumlama işlemi

Vakumlaması tamamlanıp kuruyan numuneler su jeti yardımı ile çekme, basma ve kayma numuneleri kesilmiştir. Çekme, basma ve kayma test numuneleri sırası ile ASTM D3039/D3039M-17, ASTM D6641/D6641M-16e1 ve ASTM D7078/D7078M - 12 standartlarına göre belirlenmiştir (Şekil 3). Şekil 4'te ise çekme, basma, kayma ve darbe test numuneleri görülmektedir. 


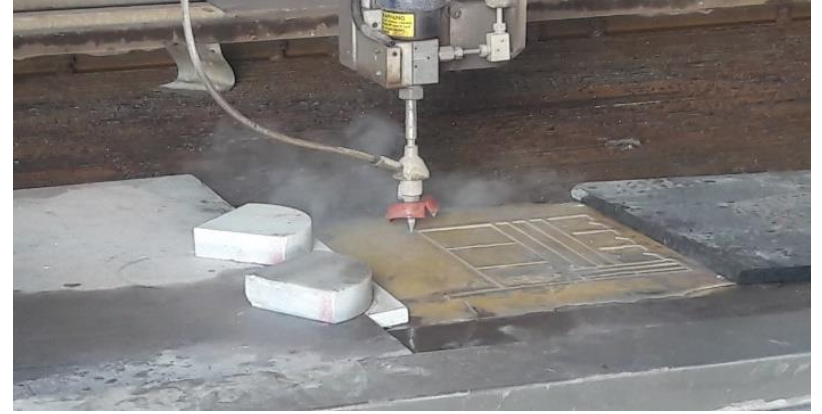

Şekil 3. Su jeti ile kesim

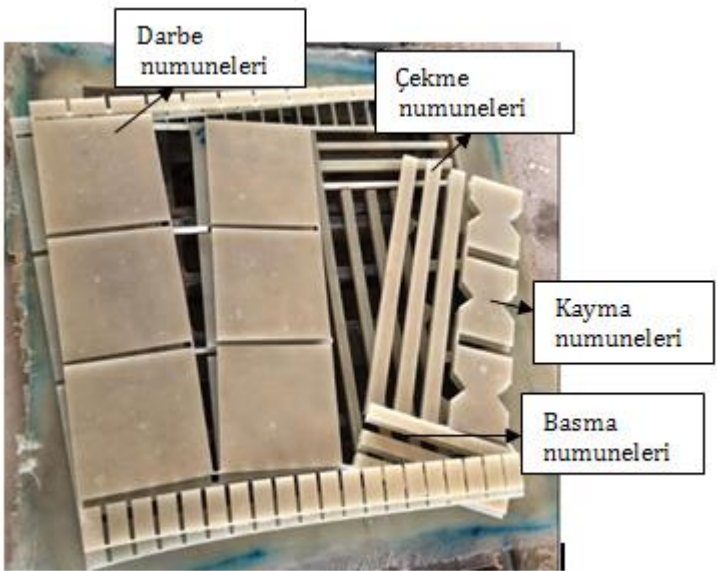

Sekil 4. Test numuneleri

Kesilmiş hibrit kompozit numunelere çekme, basma ve kayma deneyleri Dokuz Eylül Üniversitesi'nde yapılmıştır. Shimadzu AG-X çekme test cihazı kullanılmıştır (Şekil 5). Test cihazı $\pm 100 \mathrm{kN}$ yük kapasitesine sahip olup, $-70{ }^{\circ} \mathrm{C}$ ila $+350{ }^{\circ} \mathrm{C}$ sıcaklık aralıklarında test yapılmasını sağlayabilen bir kabine sahiptir. Her bir deney için 3'er adet numune kullanılmış ve elde edilen sonuçların ortalaması alınmıştır.

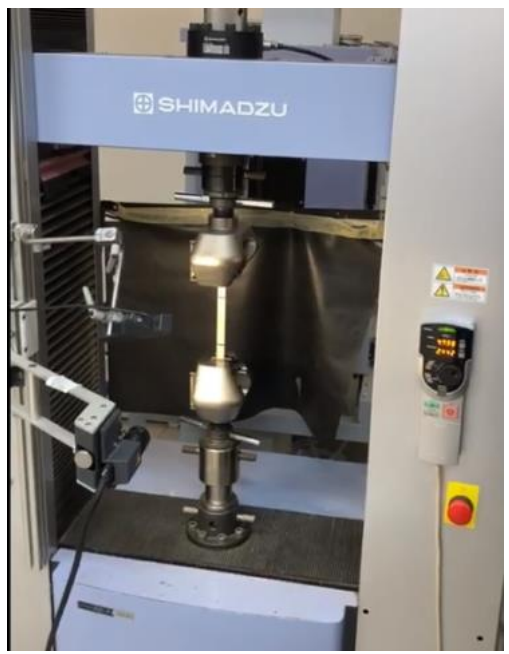

Şekil 5. Çekme test cihazı

\subsection{Darbe testleri}

Hibrit kompozitin darbe davranışının belirlenmesinde serbest ağırlık düşürme prensibine göre çalışan yer tipi sistem kontrollü ve yüksek hızlı çalışan Fractovis Plus marka darbe test cihazı kullanılmıştır (Şekil 6). Testler sırasında kullanılan ucu yarım küre şeklinde ve $12,7 \mathrm{~mm}$ çaplı vurucun kütlesi 4.926 kg'dır. Kevlar elyaf-cam elyaf/epoksi kompozit plakların darbe davranışı 30J darbe enerjisi altında ve oda sicaklığında $\left(2{ }^{\circ} \mathrm{C}\right)$ gerçekleştirilmiştir. Vurma anında vurucunun hızı $3.49 \mathrm{~m} / \mathrm{s}$ 'dir.

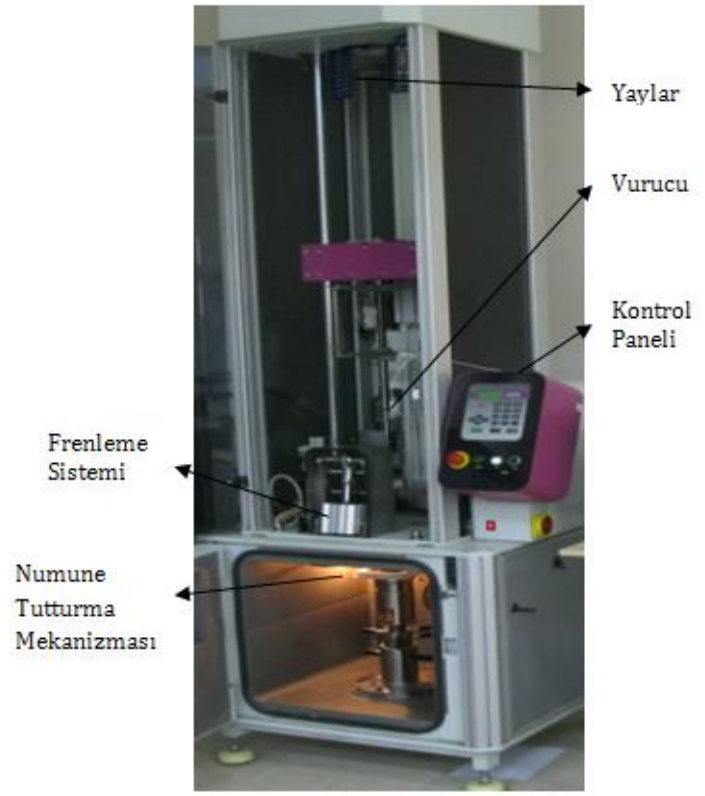

Şekil 6. Darbe test cihaz

\section{Bulgular ve tartışma}

Şekil 7'de \%0, \%1 ve $\% 3$ nanokilli kompozit numunelerin çekme deneyi grafikleri verilmiştir.

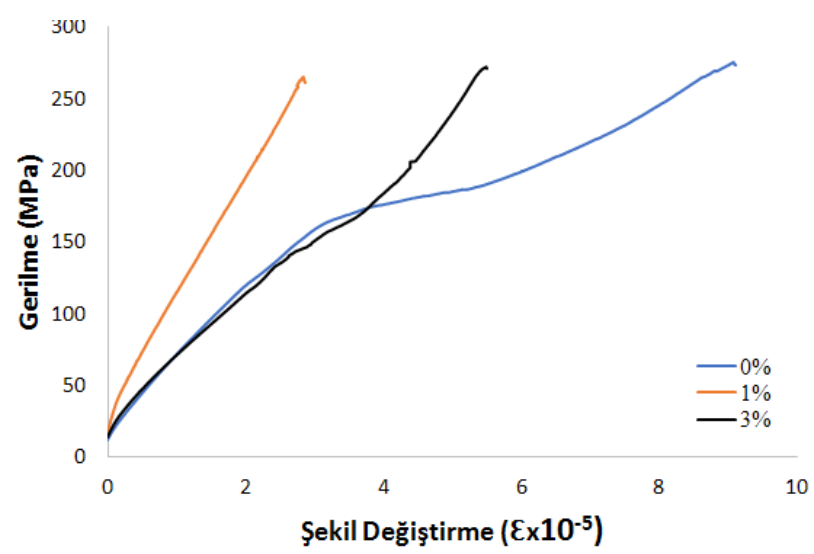

Şekil 7. Farklı nanokil oranlarına göre gerilme-şekil değiştirme diyagramı

Şekil 7' de ki $\sigma-\varepsilon$ görüleceği üzere en büyük eğim \%1 nonokilli numuneye aittir. Tablo 1'de kompozit malzemelerin mekanik özelliklerinin belirlenmesi için yaptığımız çekme ve kayma testlerinden elde edilen elastisite modülü, kayma modülü ve poisson oranı ile beraber yoğunluk değerleri verilmiştir. 
Tablo 1. Farklı nanokil oranlarına sahip hibrit kompozitin mekanik özellikleri

\begin{tabular}{lcccc}
\hline & & \multicolumn{3}{c}{ Büyüklükler } \\
\hline $\begin{array}{c}\text { Özellikler } \\
\text { Lif doğrultusunda }\end{array}$ & Sembol & $\% 0$ & $\% 1$ & $\% 3$ \\
$\begin{array}{l}\text { Elastisite Modulü } \\
\text { Lif doğrultusuna } \\
\text { dik doğrultuda }\end{array}$ & $\mathrm{E}_{1}(\mathrm{GPa})$ & 6.97 & 10.8 & 6.74 \\
$\begin{array}{l}\text { Elastisite Modulü } \\
\text { Kayma Modulü }\end{array}$ & $\mathrm{E}_{2}(\mathrm{GPa})$ & 6.97 & 10.8 & 6.74 \\
$\begin{array}{l}\mathrm{G}_{12} \\
\text { Poission Oranı }\end{array}$ & $\mathrm{U}_{12}$ & 0.26 & 0.2 & 0.25 \\
$\begin{array}{l}\text { Yoğunluk } \\
\text { Lif doğrultusunda }\end{array}$ & $\rho\left(\mathrm{g} / \mathrm{cm}^{3}\right)$ & 1.208 & 1.312 & 1.458 \\
$\begin{array}{l}\text { Çekme dayanımı } \\
\text { Lif doğrultusuna } \\
\text { dik doğrultuda }\end{array}$ & $\mathrm{X}_{\mathrm{t}}(\mathrm{MPa})$ & 264 & 271 & 268 \\
$\begin{array}{l}\text { Çekme dayanımı } \\
\text { Kayma dayanımı }\end{array}$ & $\mathrm{Y}_{\mathrm{t}}(\mathrm{MPa})$ & 264 & 271 & 268 \\
\hline
\end{tabular}
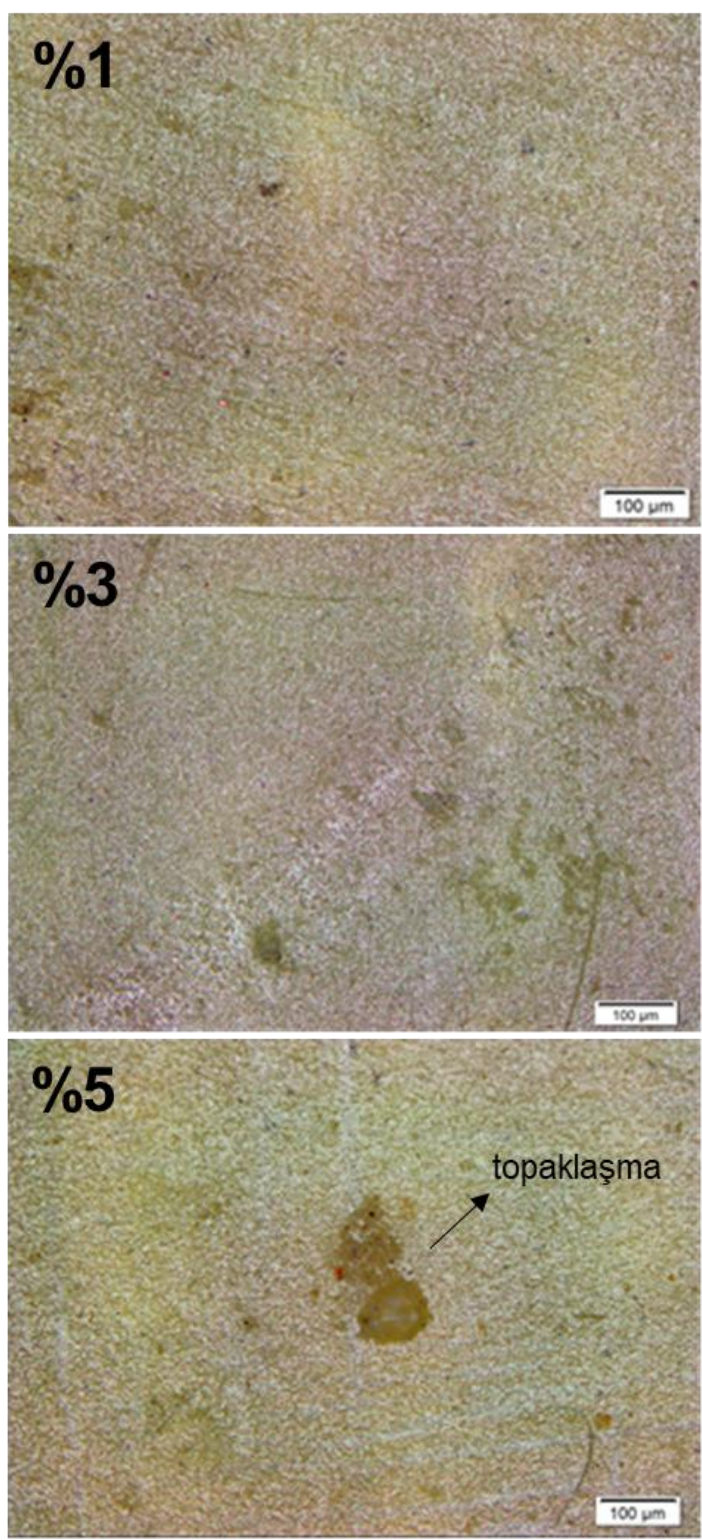

Şekil 8. \%0, \%1 ve \%3 nanokil ilaveli numunelerin optik mikroskop görüntüleri
Tablo 1'de görüleceği üzere \%1 nanokil ilavesi ile malzemenin elastisite modülünde yaklaşık \%55 artış gözlenirken; \%3 nanokil ilavesinde ise \%3 azalma görülmüştür. Nanokil oranı artması malzemede topaklaşmanın artmasına sebep olduğundan mekanik özelliklerin düşüş olabileceği kanısına varılmıştır (Şekil 8). Nanokil lokal olarak epoksiyi içine çekerek epoksinin yapısını bozmaktadır. Bu da istenilmeyen bir durumdur. Düşük oranda nanokilin epoksi içerisinde iyi absorbe olması matriks-fiber ara yüzeyini güçlendirmesini sağlayarak mekanik dayanımının iyileşmesine katkıda bulunmaktadır [14].

Kuvvet-çökme eğrileri açık ve kapalı olmak üzere iki farklı karakteristik davranış sergilemektedir. Vurucu ucun kompozit plakaya temasindan sonra geri sekmesi durumunda kapalı tip eğri grafiği vermektedir. Bu durum kompozit plakaya uygulanan enerjinin büyük kısmının numunede absorbe edildiğini absorbe olmayan kısmının da geri sektiği şeklinde yorumlanmaktadır. Açık eğri tipi ise kapalı tip eğriden farklı olarak vurucunun kompozit plakaya saplandığ veya delindiği durumlarda görülmektedir. Vurucu ucun numuneye temasından sonra geri sekmenin olmadığı ve kompozit tabaka boyunca hareket ederek delinme olayının gerçekleştiği bir süreçtir [15].

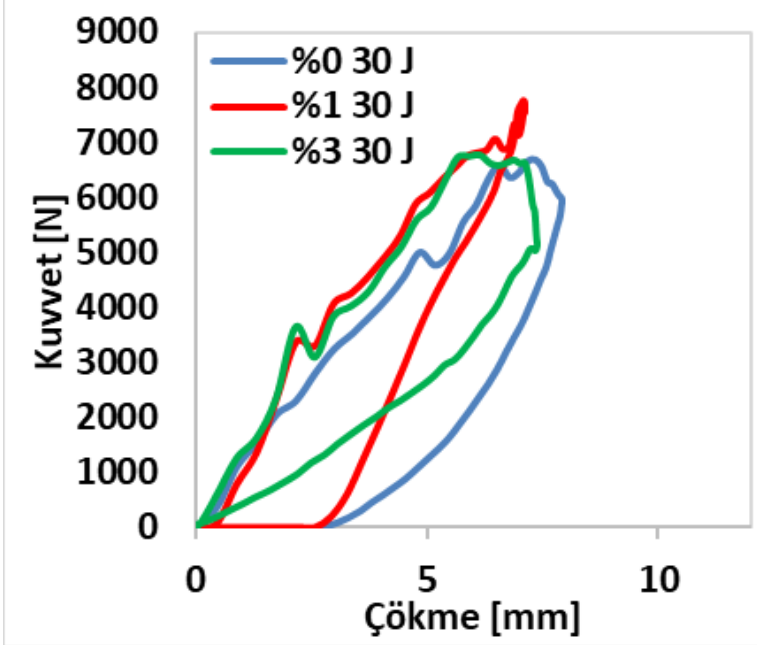

Şekil 9. 30J darbe enerjisi uygulanan $\% 0, \% 1, \% 3$ nanokil ilaveli numunelerin kuvvet-çökme eğrileri

Kuvvet-çökme eğrilerinin (Şekil 9) tamamının kapalı eğri oluşturduğu görülmektedir. Kapalı eğri vurucu uçun numune üzerine çarpıp geri sekmesi ile oluşan eğridir. Kapalı eğri de delinme hasarı oluşmaz ve numune daha az hasara uğrar. Ayrıca artan oranda nanokil ilavesinin kapalı tip eğri modelini değiştirmediği gözlemlenmiştir. Diğer taraftan \%1 nanokil ilave kompozit yapıların yük taşıma kapasitesi diğer nanokil ilaveli yapılara göre daha iyi olduğu tespiti yapılabilir. Ayrıca \%1 nanokil ilaveli numune de kapalı tip eğrinin daha dar olduğu görülmektedir. Bu durum numunede oluşan deformasyonun daha az olduğunun göstergesidir. 


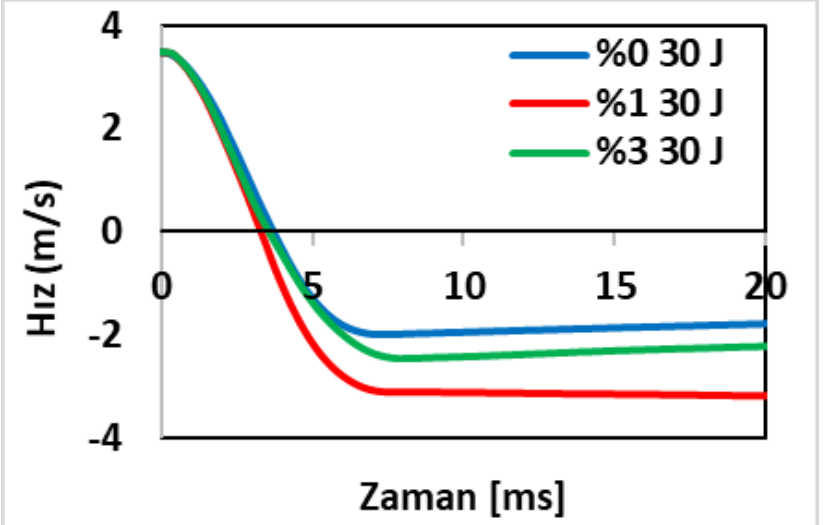

Şekil 10. 30J darbe enerjisi uygulanan ağırlıkça farklı nanokil oranlarına sahip numunelerin hız-zaman eğrileri

Şekil 10'da her bir nanokil ilaveli cam/kevlar kompozit yapıları hız-zaman grafiklerinde eğrilerin negatif bölgede olduğu görülmüştür. Bu durum belli bir hızdaki vurucunun kompozit yapıya temasından sonra hızında azalma oluştuğu ve vurucunun ters yönde hızlanması ile geri sekme meydana geldiğini ve numunede delinme hasarının oluşturmadığını söyleyebiliriz.

Hiz-zaman grafiklerinde darbe enerjisinin artmas1 durumunda belli bir hıza sahip vurucu ucun kompozit yapı ile ilk teması sonrası hızı azalır bu durumda eğer vurucu kompozit yapıdan geri seker ise yukarı doğru hareken eden vurucu uç hızı negatif bölgede gösterecektir. Aksi durumda vurucunun kompozit yapıya saplanması durumunda belli bir hız ile kompozit yapıya temas eden vurucu numuneye saplanacak ve hızı sıfır olacaktır. Bir diğer durumda ise, vurucunun numuneyi delmesi durumunda vurucunun hizı vurucu-kompozit yap1 arasındaki sürtünmeden hızı yavaşlayacak fakat geri sekme oluşmadığından dolayı eğri pozitif bölgede bulunacaktır [15].

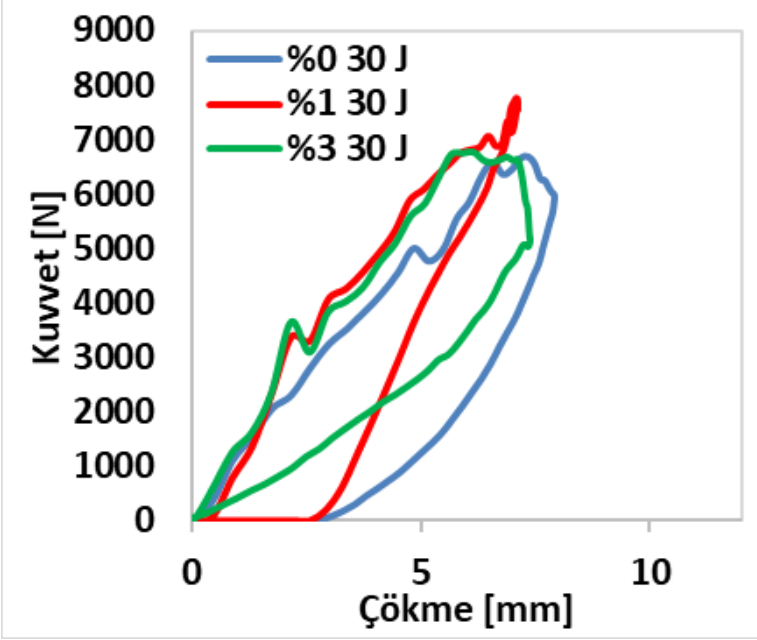

Şekil 11. 30J darbe enerjisi uygulanan \%0, \%1, \%3 nanokil ilaveli numunelerin enerji-zaman eğrileri
Şekil 11'de parabolik eğriler incelendiğinde vurucunun sahip olduğu enerjinin tüm numunelerde absorbe edilmediği görülmektedir. Absorbe edilmeyen enerjinin geri sekme oluşturduğu ve kompozit yapıda herhangi bir saplanma ve/veya delinme hasarı olmadığı görülmektedir. Bu çıkarım nanokil ilavesinin delaminasyonu minimize ederek enerji emilimini sağladığını ortaya çıkarmaktadır ve bu Alomari vd. [16] nanokilin tabakalar arası kayma dayanımını arttırarak delaminasyonu azalttığı hipotezini doğrulamaktadır. Şekil 11 'de $\% 1$ ağ. nanokil ilaveli numunenin $\% 0$ ve $\% 3$ nanokil ilaveli numunelere oranla daha az enerji absorbe ve nanokil ilaveli tabakalar arası kayma mukavemetinin artışından dolayı laminatların enerji emme kapasitesini azaldığı görülmüştür.

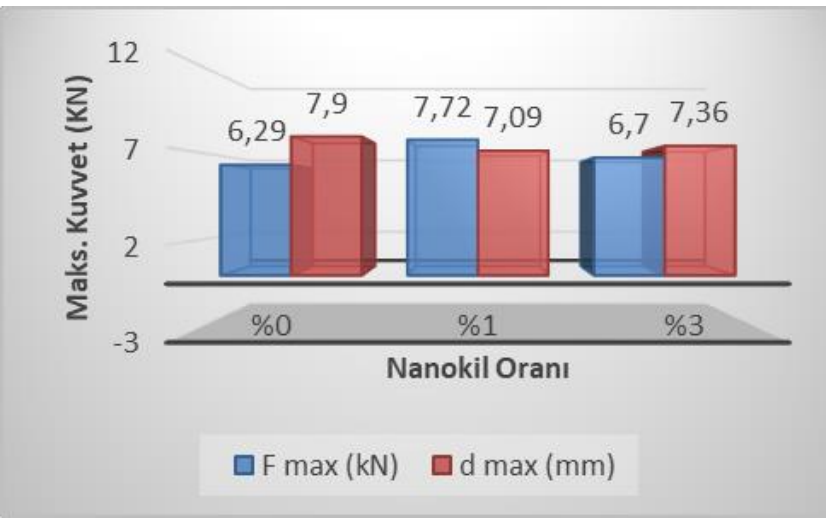

Şekil 12. 30J darbe enerjisi uygulanan farklı nanokil oranlarına sahip numunelerin maksimum kuvvetmaksimum çökme grafikleri

Şekil $12^{‘}$ den $\% 1$ nanokil ilaveli numunelerin diğer nanokil oranlı (\%0 ve \%3) numunelere göre daha fazla yük taşıma kapasitesini sağladığı görülmektedir. Ayrıca \%1 ağ. nanokil ilaveli kompozit yapıların sertliği arttırarak çökmede azalmaya sebep olmuştur. Tablo 2'de \%0, \%1, \%3 nonokil ilaveli kompozit numunelerin vickers sertlik değerleri verilmiştir. Rafiq vd. [8] nanokil ilaveli (\%1,5- \%3) cam hibrit kompozitlerde düşük nanokil ilaveli yapılarda sertliğinin \%11, mekanik dayanımının da \%23 oranında iyileştirdiği görülmüştür. \%3 nanokil ilavesindeki mekanik dayanımında yaşanılan düşüşün kil topaklanmasının matriks-fiber arayüzeyinde düzensiz yapısal bağlanmalara neden olduğunu tespit etmişlerdir. Reçine ve lifler arasındaki mikro boşluğun yapışmayı azalttığı gibi sertliğinde azalmasına sebep olduğunu belirtmişlerdir.

Tablo 2. Farklı nanokil oranlarına göre Vickers sertlik değerleri

\begin{tabular}{cccc}
\hline & \multicolumn{3}{c}{ Numuneler } \\
\hline & $\%$ nanokil & $\% 1$ nanokil & $\% 3$ nanokil \\
Vickers Sertlik & ilaveli & ilaveli & ilaveli \\
değerleri & numuneler & numuneler & numuneler \\
& 21.75 & 23.60 & 19.30 \\
\hline
\end{tabular}



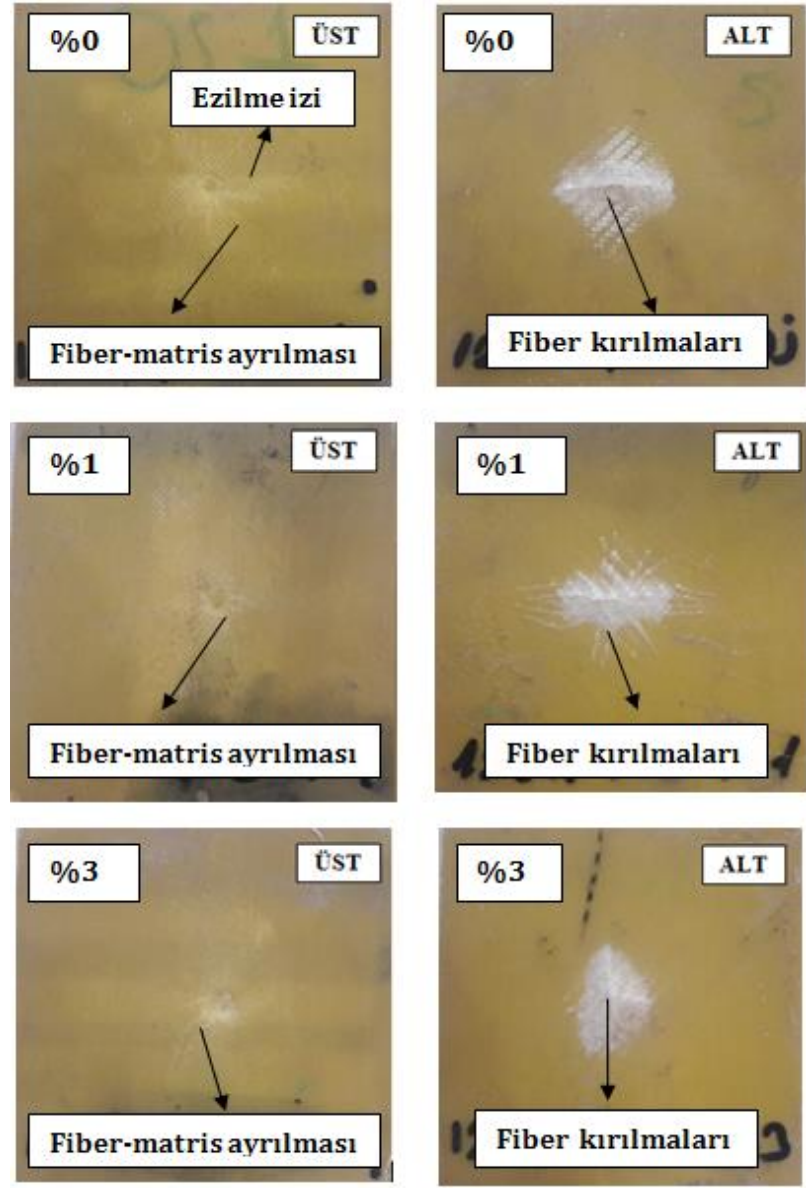

Şekil 23. Numunelerin 30 Joule darbe enerjisi uygulanması sonrası üst ve alt yüzey hasar fotoğrafları

Şekil 13'de nanokil ilavesinin üst hasar bölgesinde diğer nanokil ilaveli yapılara göre en fazla \%1 ağ. nanokil ilaveli cam/kevlar kompozitlerde çatlak alanını azalttığı görülmüştür. Alomari vd. [16] yaptıkları çalışmada kevlar esaslı hibrit kompozit yapılarda nanokil ilaveli numunelerde (\%4.3 ve \%9.4 ağ.) düşük katkılı olan yapılarda fiber-matriks ayrılmasının daha az olduğunu belirtmişlerdir. Bunun da epoksi içerisine emdirilmiş nanokilin penetrasyonunun ne kadar iyi olursa hasar bölgesinin daha da darbe direncine etkili olabileceğini göstermişlerdir.

\section{Sonuçlar}

$\mathrm{Bu}$ çalışmada, fonksiyonelleştirilmiş nanokil ilavesinin (\%0, \%1 ve \%3 ağ.) değişimleri hibrit kompozit plakaların mekanik özelliklerine darbe davranışına etkisi incelenmiştir. Farklı nanokil oranlarına sahip kompozit numunelere 30J darbe enerjisi altında yapılan darbe testleri sonucundaki darbe davranışları için aşağıdaki sonuçlara ulaşılmıştır.

- Hasar modları matris çatlağı, fiber kırılması ve fibermatris ayrılması ve fiber kırılmaları şeklindedir.

- Tüm nanokil oranları (\%0, \%1ve \%3) için numunenin darbe uygulanmayan alt yüzeydeki deformasyon alanının darbe uygulanan üst yüzeye göre daha büyük olduğu görülmüştür.

- Kompozit numuneler hazırlanırken ilave edilen ağırlıkça \%1 oranında nanokilin kompozit numunenin elastisite modülünü \%55 oranında arttırdığı; \%3 nanokil ilavesinin $\% 3$ oranında azalttığ

- \%1 ağ. nanokil ilavesinde elde edilen hibrit kompozit yapılardaki sertlik nanokil ilavesiz numunelere göre $\% 9$ oranında artırdığı gözlemlenirken, \%3 oranındaki nanokil ilavesinin sertliği \%11 oranında azalttığı gözlemlenmiştir.

- 30J darbe enerjisinde yapılan deneylerde, ağırlıkça \%1 nanokil ilaveli numunelerin çökme değerleri \%10 civarında azalırken, \%3 nanokil ilaveli numunelerde çökme değerinin \%6 oranında azaldığ 1 görülmüştür.

- Yine 30J darbe enerjisinde yapilan deneylerde, ağırlıça $\% 1$ oranında nanokil ilavesinin yük taşıma kapasitesini $\% 22$ oranında artırdığı görülürken, \%3 nanokil ilavesinin yük taşıma kapasitesini $\% 6$ oranında arttırmıştır

- Nanokilin tabakalar arası kayma dayanımın artırarak çökme ve fiber-matriks ayrılmasını azalttığı görülmüştür. $\mathrm{Bu}$ azalma en belirgin ağırlıç̧a \%1 nanokil eklenmesiyle elde edilen hibrit kompozit numunelerde görülmüştür.

- Hibrit kompozit malzemeler hazırlanırken, \%1 ağ. nanokil ilavesinin diğer nanokil oranlarına göre ( $\% 0, \% 3 \mathrm{ağ}$.) mekanik ve darbe dayanımını arttırdığ 1 görülmüştür.

Topaklaşma oluşumunu daha da azaltacağından yola çıkarak numune hazırlama aşamasında mekanik karıştırıcı yerine ultrasonik karıştırıcı kullanımının daha yüksek kil oranlarında daha iyi mekanik özelliklerin elde edilebileceği düşünülmektedir.

\section{Teşekkür}

$\mathrm{Bu}$ çalışma, Süleyman Demirel Üniversitesi Bilimsel Araştırma Projeleri Koordinasyon Birimi (SDÜ-BAP) 5056YL1-17 no'lu proje kapsamında desteklenmiştir.

\section{Çıkar çatışması}

Yazarlar çıkar çatışması olmadığını beyan etmektedir.

Benzerlik oranı (iThenticate): $\% 17$

\section{Kaynaklar}

[1] S. T. Jenq and J. J. Mo, Ballistic impact response for two-step braided three dimensional textile composites. American Institute of Aeronautics and Astronautics, 34 (2), 375-384, 1996. https://doi.org/10.2514/3.13074

[2] A. K. Kaw, Mechanics of Composite Materials. Taylor and Francis, Florida, 2005.

[3] M. Aktaş, C. Ataş, B. M. İçten and R. Karakuzu, An experimental investigation of the impact response of composite laminates. Composite Structures, 87 (4), 307-313, 2009. https://doi.org/10.1016/j.compstruct. 2008.02.003

[4] S. L. Valença, S. Griza, V. G. Oliveira, E. M. Sussuchi and F. G. C. Cunha, Evaluation of the mechanical behavior of epoxy composite reinforced with kevlar plain fabric and glass/kevlar hybrid fabric. Composites Part B: Engineering, 70, 1-8, 2015. https://doi. org/10.1016/j.compositesb.2014.09.040

[5] A. Kaştan, Y. Yalçın, H. Ünal and Ş. Talaş, PA 6/ YYPE / Nanokil kompozitlerin mekanik özelliklerinin incelenmesi. Afyon Kocatepe Üniversitesi, Fen ve Mühendislik Bilimleri Dergisi, 15 (1), 9-20, 2015. https://doi.org/10.5578/fmbd.8851 
[6] J. A. M. Ferreira, P. Reis, J. D. M. Costa and M. O. W. Richardson, Fatigue behaviour of kevlar composites with nanoclay-filled epoxy resin. Journal of Composite Materials, 47 (15), 1885-1895, 2012.

[7] K. Krushnamurty, I. Srikanth, B. Rangababu, S. K. Majee, R. Bauri and C. Subrahmanyam, Effect of nanoclay on the toughness of epoxy and mechanical, impact properties of E-glass-epoxy composites. Advanced Materials Letters, 6 (8), 684-689, 2015. https://doi.org/10.1177/0021998312452024

[8] A. Rafiq, N. Merah, R. Boukhili and M. Al-Qadhi, Impact resistance of hybrid glass fiber reinforced epoxy/nanoclay. Polymer Testing, 57, 1-11, 2017. https://doi.org/10.1016/j.polymertesting.2016.11.005

[9] M. Uyaner, M. Kara ve N. Ataberk, E Camı/epoksi tabakalı kompozitlerin düşük hızlı darbe davranışına numune boyutlarının etkisi. 8. Uluslararası Kırılma Konferans1, sayfa 361-368, İstanbul, Türkiye, 7-9 Kasim 2007.

[10] P. N. B. Reis, J. A. M. Ferreira, P. Santos, M. O. W. Richardsoni and J. B. Santos, Impact response of kevlar composites with filled epoxy matrix. Composite Structures, $94 \quad$ (12), 3520-3528, 2012. https://doi.org/10.1016/j.compstruct.2012.05.025

[11] G. Öner, H. Y. Ünal ve Y. Pekbey, Karbon nanotüp katk1lı cam lifi-epoksi kompozitlerin termal ve eğilme özelliklerinin araştırılması. Dicle Üniversitesi
Mühendislik Fakültesi Mühendislik Dergisi, 8 (4), 805 816, 2017.

[12] T. H. Mahdi, M. E. Islam, M. V. Hosur and S. Jeelani, Low-velocity impact performance of carbon fiberreinforced plastics modified with carbon nanotube, nanoclay and hybrid nanoparticles. Journal of Reinforced Plastics and Composites, 36 (9), 696-713, 2017. https://doi.org/10.1177/0731684417693429

[13] R. Şimşek, Cam-kevlar elyaf/epoksi hibrit kompozitlerin darbe davranışları üzerine fonksiyonellendirilmiş nanokil ilavesinin etkisi. Yüksek Lisans Tezi, Süleyman Demirel Üniversitesi Fen Bilimleri Enstitüsü, Türkiye, 2019.

[14] M. F. Saraç, M. Mert, İ. Bülbül, İ. Aktitiz, B. S. Yalçın ve R. Varol, Stereolitrografi ile 3B basılabilir nanokil takviyeli polimer yapıların mekanik karakterizasyonu. Iğdır Üniversitesi Fen Bilimleri Enstitüsü Dergisi, 9(3), 1584-1593, 2019. https://doi.org/10.21597/jist.555398

[15] M. Sayer, Hibrit kompozitlerin darbe davranışlarının incelenmesi. Doktora Tezi, Pamukkale Üniversitesi Fen Bilimleri Enstitüsü, Türkiye, 2009.

[16] A. Alomari, S. Aldajah, S. Hayek, K. Moustafa and Y. Haik, Experimental investigation of the low speed impact characteristics of nanocomposites. Materials Design, 47, 836-841, 2013. https://doi.org/10.1016 /j.matdes.2012.12.079 